\section{Gefährliche Tattoos}

A zofarbstoffe können in der Haut zu karzinogenen Aminen umgebaut werden und sind deshalb größtenteils in Kosmetika verboten. Nicht so streng kontrolliert werden aber offensichtlich Farbpigmente für Tätowierungen, in denen sich zahlreiche eigentlich verbotene Azoverbindungen - wie z. B. Pigment Red 22 - befinden. Eine Regensburger Forschergruppe engagierte deshalb professionelle Tätowierer und ließ sie gängige Motive auf operativ entfernte Patientenhaut sowie auf Schweinehaut applizieren. Die anschließend in der Haut gemessenen Pigmentkonzentrationen betrugen zwischen 0,6 und 9,4 mg pro $\mathrm{cm}^{2}$. Diese Befunde sollten nun einer Risikoevaluation unterzogen werden, wünschen sich die Autoren. Auch sollten Dermatologen Hautprob-

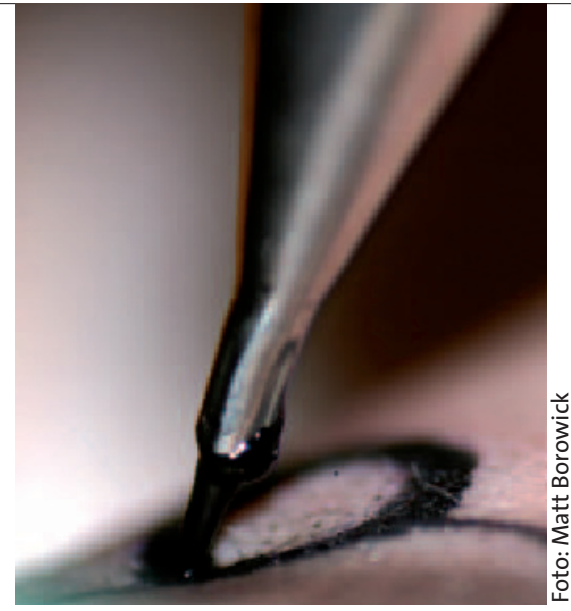

leme in Verbindung mit Tattoos systematisch dokumentieren. Bisher existieren nur anekdotische Berichte über allergische Reaktionen, epidermale Hyperplasien sowie Hautkrebs im Bereich der Tätowierungen.

$b k$

Engel E et al. Contact Dermatitis 2008; 58:228-33

\title{
Sarkoidose nach Hyposensibilisierung
}

D ie Ätiologie der Sarkoidose ist nicht geklärt, Fremdkörper könnten als Auslöser eine Rolle spielen. Das sollte auch bei einer spezifischen Immuntherapie bedacht werden: Bei einer 49-jährigen Frau mit allergischem Asthma bronchiale entwickelten sich drei Jahre nach Abschluss einer dreijährigen Hyposensibilisierung kleine subkutane Knoten, die nach Biopsie als Sarkoidose-Granulome identifiziert wurden. Sie waren streng auf das subkutane Gewebe begrenzt, symptomlos und verschwanden spontan in- nerhalb von zwei Monaten. Tatsächlich hatte die Patientin vor der Immuntherapie bereits zwei akute Sarkoidose-Schübe durchgemacht, die auf Glukokortikoide gut angesprochen hatten. Die subkutanen Veränderungen waren im Rahmen eines erneuten Schubes aufgetreten. Da sie sich genau an den Injektionsstellen der Immuntherapie befanden, ist ein Zusammenhang wahrscheinlich.

\section{$b k$}

Marcoval J et al. Clin Exp Dermatol 2008; 33: $132-4$

\section{Hus h 1 - ein neues Allergen aus Beluga-Kaviar}

$M$ it einer Ei-Allergie der besonderen Art wurde eine 55-jährige Frau vorstellig, die zweimal nach dem Genuss von Beluga-Kaviar starke Bauchkrämpfe, Übelkeit und Durchfall durchlitten hatte. Als Auslöser der Allergie konnte schließlich Vitellogenin identifiziert werden. Dieses Protein kommt im Eigelb ver-

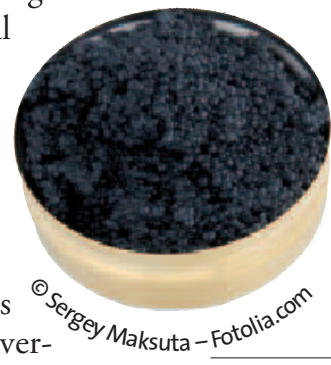

Allergen identifiziert, die Homologie zum Stör-Vitellogenin ist allerdings gering. Auch mit den Vitellogeninen anderer Kaviararten bestehen nur schwache Homologien, so dass die Autoren das Beluga-Kaviar-Vitellogenin als eigenständiges Allergen definieren und den Namen Hus h 1 vorschlagen. $\quad b k$ schiedener Fischeier vor. Auch in Hühnereigelb wurde Vitellogenin bereits als
Perez-Gordo M et al. Allergy 2008; 63: $479-80$

\section{Schutzlose Ekzemhände}

ie Grenzwerte der maximalen Arbeitsplatzkonzentration für die Lösungsmittel Xylol und Toluol sind Grenzwerte der Luftbelastung, da die systemische Aufnahme der flüchtigen Substanzen primär über die Atemwege erfolgt. Hiervon gibt es allerdings Ausnahmen: Arbeiter mit atopischer Dermatitis oder Kontaktekzemen der Hände nehmen Xylol und Toluol vermehrt auch über die Haut auf, so das Ergebnis einer Untersuchung in einer japanischen Autolackiererei. Je mehr die Hautbarriere gestört war, desto mehr Lösungsmittel wurde aufgenommen. Wie sich die Arbeiter wirksam schützen können, ist allerdings unklar: In der Studie trugen die getesteten Personen bereits Nylonschutzhandschuhe und verwendeten Hautpflegeprodukte. Dadurch konnten die stark lipophilen Lösungsmittel aber offensichtlich nicht an der Hautpenetration gehindert werden.

$b k$

Hino R et al. Contact Dermatitis 2008; 58 : 76-9

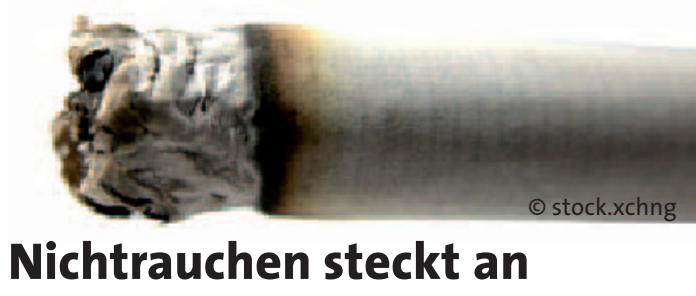

W enn ein Raucher seine letzte $\mathrm{Zi}$ garette ausdrückt und zum Nichtraucher wird, kann sich das auch auf das Rauchverhalten seines sozialen Umfelds auswirken und einen Dominoeffekt auslösen. Im Rahmen der Framingham Heart Study wurden die Daten von 12.067 Personen von 1971 bis 2003 dokumentiert. Die Forscher stellten „Cluster“ von Rauchern bzw. Nichtrauchern fest. Eine Änderung des Rauchverhaltens betraf oft die ganze Gruppe. Der Nachahmeffekt war umso stärker, je enger die soziale Bindung zu demjenigen war, der mit dem Rauchen aufhörte: So zogen Ehepartner zu 67\% nach, Freunde zu 36\% und Arbeitskollegen zu 34\%, wenn ein Raucher mit gutem Vorbild vorangegangen war.

Christakis NA et al. N Engl J Med 2008; 358: 2249-58 